\title{
Assessment of Factors Associated with Adherence to Iron-Folic Acid Supplementation Among Urban and Rural Pregnant Women in North Western Zone of Tigray, Ethiopia: Comparative Study
}

\author{
Abel Gebre ${ }^{1, *}$, Afework Mulugeta ${ }^{2}$, Belachew Etana ${ }^{2}$ \\ ${ }^{1}$ College of Health Science, Department of Public Health, Samara University, Samara, Ethiopia \\ ${ }^{2}$ College of Health Science, Department of Public Health, Mekelle University, Mekelle, Ethiopia
}

Email address:

abelgebre21@gmail.com (A. Gebre), afework.mulugeta@gmail.com (A. Mulugeta), ba.etana@gmail.com (B. Etana)

To cite this article:

Abel Gebre, Afework Mulugeta, Belachew Etana. Assessment of Factors Associated with Adherence to Iron-Folic Acid Supplementation Among Urban and Rural Pregnant Women in North Western Zone of Tigray, Ethiopia: Comparative Study. International Journal of Nutrition and Food Sciences. Vol. 4, No. 2, 2015, pp. 161-168. doi: 10.11648/j.ijnfs.20150402.16

\begin{abstract}
Introduction: Iron deficiency is the leading nutrient deficiency in the world affecting the lives of more than 2 billion people, accounting to over $30 \%$ of the world's population. Pregnant women are particularly at high risk of iron deficiency. Objective: To determine and compare the adherence rate and identify factors associated with iron folic acid supplementation among urban and rural pregnant women attending antenatal clinics in North Western Zone of Tigray, Ethiopia. Methods: An institution based comparative cross sectional study was employed among 358 urban and 356 rural pregnant women attending antenatal clinics in North Western Zone of Tigray from March to April 2014. Logistic regression analysis was used to identify factors associated with adherence to iron-folic acid supplementation among urban and rural pregnant women. All tests were two-sided and $\mathrm{p}$ value $<0.05$ was considered statistically significant. Results: The rate of adherence to iron folic acid supplementation among the pregnant women in the urban and rural communities was 37.2\% $(95 \% \mathrm{CI}, 32.26 \%$ $42.25 \%)$ and $28.9 \%(95 \% \mathrm{CI}, 24.4 \%-33.81 \%)$ respectively indicating that there was no significant difference among the two groups with regard to adherence to iron-folic acid supplementation. The independent predictors for maternal adherence to iron folic acid supplementation were early registration $(\mathrm{AOR}=1.778,95 \% \mathrm{CI}=1.076-2.936)$, having four or more visits $(\mathrm{AOR}=3.784,95 \% \mathrm{CI}=2.073-6.909)$, previous anemia $(\mathrm{AOR}=1.913,95 \% \mathrm{CI}=1.135-3.223)$, and current anemia $(\mathrm{AOR}=0.408$, $95 \% \mathrm{CI}=0.224-0.744)$ for urban pregnant women. Similarly, elderly age $(\mathrm{AOR}=0.527,95 \% \mathrm{CI}=0.315-0.881)$, early registration $(\mathrm{AOR}=1.918,95 \% \mathrm{CI}=1.116-3.296)$, previous anemia $(\mathrm{AOR}=2.472,95 \% \mathrm{CI}=1.352-4.517)$ and current anemia $(\mathrm{AOR}=0.400$, $95 \% \mathrm{CI}=0.214-0.749)$ were the independent predictors for maternal adherence to iron folic acid supplementation for the rural pregnant women. Conclusion: Adherence rate to iron-folic acid supplementation in both urban and rural communities were very low. Comprehensive nutrition education should focus on the importance of adherence to iron folic acid tablets both for urban and rural pregnant women.
\end{abstract}

Keywords: Adherence, Pregnant, Iron-folic Acid, Tigray, Ethiopia

\section{Introduction}

Iron deficiency is the leading single nutrient deficiency in the world affecting the lives of more than 2 billion people, accounting to over $30 \%$ of the world's population particularly in developing countries [1]. Pregnant women are particularly at high risk of iron deficiency due to increased nutrient requirement during pregnancy $[2,3]$.

Iron deficiency anemia contributes adverse effects on mother and child health. Maternal risks including low weight gain, preterm labour, placenta previa, premature rupture of membrane, cardiac arrest, hemorrhage, lowered resistance to infection, poor cognitive development and reduced work capacity. Similarly, fetal and neonatal risks include prematurity, low birth weight, fetal distress which contribute to perinatal morbidity and mortality as well as infants born to 
anemic mothers will more likely to become anemic themselves $[4,5]$. Folic acid deficiency at conception and in early pregnancy is associated with increased risk of neural tube defects and other adverse pregnancy outcomes such as preeclampsia, malformations such as orofacial clefts, spontaneous abortion, fetal death, fetal growth restriction and preterm delivery $[6,7]$.

Anemia during pregnancy is defined by the Centers of Disease Control and prevention as a hemoglobin $<11 \mathrm{~g} / \mathrm{dl}[8]$. Current estimates from the World Health Organization (WHO) put prevalence of anemia at $41.8 \%$ among pregnant women, with the highest prevalence rate $(61.3 \%)$ found among pregnant women in Africa and 52.5\% among South East Asia. Globally, iron deficiency anemia is associated with $22 \%$ of all $(115,000)$ maternal deaths [9, 10]. In Ethiopia, $17 \%$ of reproductive age women are estimated to be anemic and particularly $22 \%$ of pregnant women are anemic from which $18 \%$ are found in rural and $11 \%$ are in urban residents $[11,12]$.

According to the WHO and Ethiopia's national guidelines for control and prevention of micronutrient deficiencies, all pregnant women should receive and consume a standard dose of $60 \mathrm{mg}$ iron $+400 \mu \mathrm{g}$ folic acid daily for 6 months starting from the first month of pregnancy or at the time of their first antenatal visit [13-16]. Currently, iron-folic acid supplementation (IFA) is the main strategy for anemia control and prevention in Ethiopia [14, 17].While many developing countries including Ethiopia are now implementing IFA supplementation through antenatal care programs, only few countries have reported significant improvement in IFA supplementation and anemia control and prevention $[4,12,18]$. This low achievement may be related with poor access to and utilization of prenatal care services, inadequate supply of IFA tablets, poor counseling, lack of knowledge on anemia, and certain beliefs $[9,12]$. However, many studies suggested that poor maternal adherence to the regimen is the main reason for the ineffectiveness of the strategy $[4,9,19]$. Adherence to a medication regimen is generally defined as the extent to which patients take medications as prescribed by their health care providers [20]. Adherence rates for individual patients are usually reported as the percentage of the prescribed doses of the medication actually taken by the patient over a specified period $[4,9]$.

In Ethiopia, the overall national data suggests that from all pregnant women supplemented with IFA tablets only $0.4 \%(1 \%$ and $0.3 \%$ in urban and rural respectively) consumed $>90$ tablets during their pregnancy time $[11,12,14]$.This indicates that identification of the factors associated with adherence to IFA supplement is an important step to improve the IFA tablets use among pregnant women in urban and rural areas of the country. However, there was no previous study that has been conducted in the study area with this purpose. Therefore, the aim of this study was to determine and compare adherence rate and identify factors associated with Iron Folic Acid supplementation among urban and rural pregnant women attending antenatal clinics found in North Western Zone of Tigray, Northern Ethiopia, 2014.

\section{Methods}

\subsection{Study Design}

An institutional based comparative cross-sectional study was used to conduct the study.

\subsection{Study Population}

A total of 714 pregnant women (356 from rural and 358 from urban) communities who were previously supplemented with iron-folic acid tablets to them and attending routine antenatal care follow up for the current pregnancy were enrolled in the study from March to April 2014 from ten randomly selected health institutions found in North Western Zone of Tigray, Ethiopia.

\subsection{Eligibility Criteria}

Pregnant women who came at least for second visit to the antenatal clinics of the selected health institutions and previously supplemented with IFA tablets for at least one month before the date of interview. All pregnant women were excluded from the study if they have any of the following disorders including (multiple pregnancies, hemolytic anemia, mental disorder, women who are unable to hear and/or speak).

\subsection{Adherence Assessment}

Self report adherence was used by asking how many times of supplementations intake per week in the previous time. Adherence in this study was defined as pregnant women taking IFA tablets at least 4 times per week in the previous one month preceding the survey [21] .The questionnaire consisted of the following parts: Socio- demographic factors, rate of self reported adherence, obstetric and medical factors, health service related factors, mother's knowledge status and social factors.

\subsection{Statistical Analysis}

The statistical analysis was performed using computer software SPSS version 20 after the data were entered to Epiinfo version 3.5.1 and exported to it. Categorical variables were summarized as numbers and percentages, where as normally distributed continuous variables were presented as means and standard deviations.

We estimated the proportion of pregnant women among urban and rural groups who adhered to iron folic acid (yes/no) during the antenatal follow up period (percentages and $95 \%$ confidence intervals). To identify factors associated with adherence to iron-folic acid supplementation among urban and rural pregnant women, first a bivariate logistic regression was performed for each independent variable with adherence to iron-folic acid supplementation and crude odds ratio with $95 \%$ confidence intervals was obtained. Then, significant variables observed in the bivariate analysis ( $p$ value $<0.2$ ) were subsequently included in to the multivariable logistic regression to determine independent predictors of adherence to iron-folic acid supplementation among the pregnant 
women [7]. The strength of statistical association was measured by adjusted odds ratios and 95\% confidence intervals. All tests were two-sided and $\mathrm{p}$ value $<0.05$ was considered statistically significant. The goodness of fit of the final logistic model was tested using Homers and Lemeshow test at a $P$ value $>0.05$.

\subsection{Ethical Considerations}

The study was conducted after getting ethical clearance from Mekelle University, College of Health Sciences, Institutional Review Board (IRB). Support letter was obtained from Tigray Regional Health Bureau and Woreda Health Offices of the selected health facilities. Written informed consent was secured from study participants. The participants were also assured about the confidentiality of the data. While assessing anemia status, the result of the test was communicated immediately to each participant and if the pregnant woman was anemic, she was referred to the health personnel for treatment and follow-up.

\section{Results}

\subsection{Socio-Demographic Characteristics of the Study Subjects}

Table 1. Socio-demographic characteristics of urban and rural pregnant women attending antenatal clinics in North West zone of Tigray, Ethiopia, $2014(n=714)$.

\begin{tabular}{|c|c|c|}
\hline \multirow{2}{*}{ Variables } & Urban $=358$ & Rural $=356$ \\
\hline & n (\%) & n (\%) \\
\hline \multicolumn{3}{|l|}{ Age (years) } \\
\hline$<20$ & $37(10.4)$ & $60(16.9)$ \\
\hline $20-24$ & $110(30.7)$ & $104(29.2)$ \\
\hline $25-29$ & $138(38.5)$ & $85(23.9)$ \\
\hline $30-35$ & $55(15.4)$ & $82(23.0)$ \\
\hline $36^{+}$ & $18(5.0)$ & $25(7.0)$ \\
\hline \multicolumn{3}{|l|}{ Marital status } \\
\hline Married & $344(96.1)$ & $351(98.6)$ \\
\hline Divorced & $11(3.1)$ & $3(0.8)$ \\
\hline Others & $3(0.8)$ & $2(0.6)$ \\
\hline \multicolumn{3}{|l|}{ Woman's education } \\
\hline No formal education & $89(24.9)$ & $271(76.1)$ \\
\hline Primary & $103(28.8)$ & $65(18.3)$ \\
\hline Secondary & $118(33.0)$ & $19(5.3)$ \\
\hline Above secondary & $48(13.3)$ & $1(0.3)$ \\
\hline \multicolumn{3}{|l|}{ Husband's education } \\
\hline No formal education & $63(18.3)$ & $254(72.4)$ \\
\hline Primary & $62(18.1)$ & $71(20.2)$ \\
\hline Secondary & $95(27.6)$ & $24(6.8)$ \\
\hline Above secondary & $124(36.0)$ & $2(0.6)$ \\
\hline \multicolumn{3}{|l|}{ Family size } \\
\hline $1-3$ & $197(55.0)$ & $172(48.3)$ \\
\hline $4-6$ & $154(43.0)$ & $140(39.3)$ \\
\hline $6^{+}$ & $7(2.0)$ & $44(12.4)$ \\
\hline
\end{tabular}

Of the 714 study subjects, $358(50.3 \%)$ were from urban pregnant women and $356(49.7 \%)$ were from rural pregnant women (Table 1).The mean ages (+SD) of the study subjects among the urban and rural pregnant women were $25.85+$ 5.36 and $25.74+6.3$ years respectively. Majority of the subjects $(69.2 \%)$ from urban were in the age range of 20 to 29 years. Similarly, more than half $(53.1 \%)$ of the subjects from rural were in the age range of 20 to 29 years.

\subsection{Obstetric and Health Related Characteristics of the Study Subjects}

The mean current gestational age $(+\mathrm{SD})$ of the pregnant women was $30.68+5.461$ weeks and $29.40+5.779$ weeks for urban and rural pregnant women respectively (Table 2). Majority of the participants from the urban were in their third trimester $(75.4 \%)$ and $66.6 \%$ for the rural women. The mean of gestational (+SD) of the women during their first visit was $17.58+4.732$ weeks for urban and $17.78+6.235$ weeks for rural pregnant women.

Table 2. Obstetric and health service related characteristics of urban and rural pregnant women attending antenatal clinics in north west zone Tigray, Ethiopia, 2014(n=714).

\begin{tabular}{lll}
\hline Variables & Urban=358 & Rural=356 \\
\cline { 2 - 3 } $\begin{array}{ll}\text { Number of visits } \\
<4\end{array}$ & n (\%) \\
$>4$ & $74(19.6)$ & $325(91.3)$ \\
Time of registration & & $31(8.7)$ \\
$<16$ weeks(early) & $189(52.8)$ & \\
$>16$ weeks(late) & $169(47.2)$ & $168(47.2)$ \\
Nutrition counseling & & $188(52.8)$ \\
Yes & $328(91.6)$ & \\
No & $30(8.4)$ & $311(87.4)$ \\
Gravidity & & $45(12.6)$ \\
Primigravida & $112(31.3)$ & \\
Multigravida & $246(68.7)$ & $85(23.9)$ \\
Parity & & $271(76.1)$ \\
Nulliparous & $116(32.4)$ & \\
primiparous & $84(23.5)$ & $87(24.4)$ \\
Multiparous & $158(44.1)$ & $96(27.0)$ \\
Trimester & & $173(48.6)$ \\
Second & $88(24.6)$ & $119(33.4)$ \\
Third & $270(75.4)$ & $237(66.6)$ \\
\hline
\end{tabular}

\subsection{Self-Reported Rate of Adherence to IFA Supplementation}

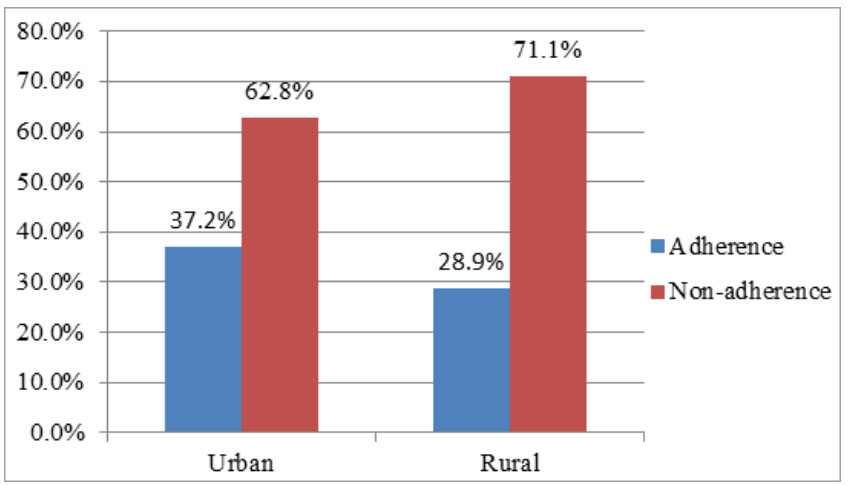

Figure 1. Self reported adherence rate to IFA supplementation among urban and rural pregnant women attending antenatal clinics in north western of Tigray, Ethiopia, June, 2014. 
The adherence rate of the urban and rural pregnant women was $37.2 \%(95 \% \mathrm{CI}, 32.26 \%-42.25 \%)$ and $28.9 \%(95 \% \mathrm{CI}$, $24.4 \%-33.81 \%$ ), respectively. This indicated that there was no significant difference among urban and rural pregnant women with regard to adherence to IFA supplementation (Figure 1).

\subsection{Factors Associated with Adherence to IFA Supplementation}

The comparison between the profiles of the pregnant women who adhered to IFA supplementation and who did not from (Table 3) the multivariable logistic regression analysis level after adjusting for each other, revealed that variables that were independent predictors for maternal adherence to IFA supplementation were early registration antenatal care $(\mathrm{AOR}=1.778,95 \% \mathrm{CI}=1.076-2.936)$, having four or more antenatal visits $(\mathrm{AOR}=3.784,95 \% \mathrm{CI}=2.073-6.909)$, anemia during the first visit $(\mathrm{AOR}=1.913,95 \% \mathrm{CI}=1.135-3.223)$ and current anemia of the pregnant women $(\mathrm{AOR}=0.408$, $95 \% \mathrm{CI}=0.224-0.744)$, indicating that early registration and having at least four antenatal visits, being anemic during the first visit could affect positively for IFA tablets intake and current anemia status could affect negatively for IFA tablets intake in the urban communities. Similarly, early registration antenatal care ( $\mathrm{AOR}=1.918,95 \% \mathrm{CI}=1.116-3.296)$, anemia during the first visit $(\mathrm{AOR}=2.472,95 \% \mathrm{CI}=1.352-4.517)$, current anemia $(\mathrm{AOR}=0.400,95 \% \mathrm{CI}=0.214-0.749)$ and elder age of the women $(\mathrm{AOR}=0.527,95 \% \mathrm{CI}=0.315-0.881)$, indicating that early registered women for antenatal service, being anemic during the first visit could affect positively for IFA tablets intake and being anemic currently and elder age women could affect negatively for IFA tablets intake in the rural communities.

Table 3. Factors associated with adherence to IFA supplementation by selected variables, among urban and rural of pregnant women in North West zone of Tigray, Northern Ethiopia, June, 2014(n=714).

\begin{tabular}{|c|c|c|c|c|}
\hline \multirow{3}{*}{ Variables } & \multicolumn{4}{|c|}{ Adherence to IFA supplementation } \\
\hline & \multicolumn{4}{|c|}{ Urban $=358$} \\
\hline & Yes $(\%)$ & No (\%) & COR $(95 \% \mathrm{CI})$ & $\operatorname{AOR}(95 \% \mathrm{CI})$ \\
\hline \multicolumn{5}{|c|}{ Marital status } \\
\hline Married & $131(38.1)$ & 213(61.9) & $3.690(0.813-6.749)$ & $3.690(0.813-6.749)$ \\
\hline Unmarried & $2(14.3)$ & $12(85.7)$ & 1 & 1 \\
\hline \multicolumn{5}{|c|}{ Early registration } \\
\hline Yes & $85(45)$ & $104(55)$ & $2.06(1.36-3.20)$ & $1.778(1.076-2.936)^{*}$ \\
\hline No & $48(28.4)$ & 121(71.6) & 1 & 1 \\
\hline \multicolumn{5}{|l|}{ No of Visits } \\
\hline$<4$ & $89(31.3)$ & $195(68.7)$ & 1 & 1 \\
\hline$>4$ & $44(59.4)$ & $30(40.6)$ & $3.213(1.896-5.446)$ & $3.784(2.073-6.909)^{*}$ \\
\hline \multicolumn{5}{|c|}{ Previous anemia } \\
\hline Yes & $50(45.5)$ & $60(54.5)$ & $1.65(1.047-2.621)$ & $1.913(1.135-3.223)^{*}$ \\
\hline No & $83(33.5)$ & $165(66.5)$ & 1 & 1 \\
\hline \multicolumn{5}{|c|}{ Current anemia } \\
\hline Yes & $24(25.8)$ & $69(74.2)$ & $0.498(0.294-0.842)$ & $0.408(0.224-0.744)^{*}$ \\
\hline No & $109(41.1)$ & $156(58.9)$ & 1 & 1 \\
\hline \multicolumn{5}{|c|}{ Nutrition counseling } \\
\hline Yes & $127(38.7)$ & $201(61.3)$ & $2.527(1.005-6.353)$ & $1.015(0.334-3.084)$ \\
\hline No & $6(20)$ & $24(80)$ & 1 & 1 \\
\hline \multicolumn{5}{|c|}{ Knowledge of anemia } \\
\hline Yes & $67(45.5)$ & $80(54.5)$ & $1.840(1.190-2.845)$ & $1.208(0.695-2.099)$ \\
\hline No & $66(31.2)$ & $145(68.8)$ & 1 & 1 \\
\hline \multicolumn{5}{|c|}{ Knowledge of IFA } \\
\hline Yes & $99(43.4)$ & $129(56.6)$ & $2.16(1.353-3.470)$ & $1.549(0.837-2.867)$ \\
\hline No & $34(26.1)$ & $96(73.9)$ & 1 & 1 \\
\hline \multicolumn{5}{|c|}{ Participate in CC } \\
\hline Yes & $113(39.1)$ & $176(6 . .9)$ & $1.573(0.888-2.785)$ & $1.091(0.531-2.238)$ \\
\hline No & $20(28.9)$ & $49(71.1)$ & 1 & 1 \\
\hline \multicolumn{5}{|c|}{ Family support } \\
\hline Yes & $125(39.0)$ & $195(61.0)$ & $2.404(1.068-5.412)$ & $1.751(0.677-4.525)$ \\
\hline No & $8(21.0)$ & $30(79.0)$ & 1 & 1 \\
\hline \multicolumn{5}{|l|}{ Trimester } \\
\hline \multicolumn{5}{|l|}{ Second } \\
\hline Third & & & & \\
\hline
\end{tabular}


Table 3. Continue.

\begin{tabular}{|c|c|c|c|c|}
\hline \multirow{3}{*}{ Variables } & \multicolumn{4}{|c|}{ Adherence to IFA supplementation } \\
\hline & \multicolumn{4}{|l|}{ Rural $=356$} \\
\hline & Yes $(\%)$ & $\mathrm{No}(\%)$ & $\operatorname{COR}((5 \% \mathrm{CI})$ & $\operatorname{AOR}(95 \% \mathrm{CI})$ \\
\hline \multicolumn{5}{|l|}{ Age (years) } \\
\hline$<25$ & $55(33.5)$ & $109(66.5)$ & 1 & 1 \\
\hline$>25$ & $48(25)$ & $144(75)$ & $0.661(0.417-1.047$ & $0.527(0.315-0.881)^{*}$ \\
\hline \multicolumn{5}{|c|}{ Marital status } \\
\hline Married & $102(29.1)$ & $249(70.9)$ & $1.639(1.181-4.838)$ & \\
\hline Unmarried & $1(20)$ & $4(80)$ & 1 & \\
\hline \multicolumn{5}{|l|}{$\begin{array}{l}\text { Husband's } \\
\text { education }\end{array}$} \\
\hline Not formal & $68(26.8)$ & $186(73.2)$ & 1 & 1 \\
\hline Formal & $34(35)$ & $63(65)$ & $1.476(0.894-2.437)$ & $1.350(0.753-2.418)$ \\
\hline \multicolumn{5}{|c|}{ Waiting time (mins) } \\
\hline$<30$ mins & $9(42.8)$ & $12(52.2)$ & $1.92(0.785-4.713)$ & $1.355(0.510-3.600)$ \\
\hline$>30$ mins & $94(28)$ & $241(72)$ & 1 & 1 \\
\hline \multicolumn{5}{|c|}{ Early registration } \\
\hline Yes & $54(32.1)$ & $114(67.9)$ & $1.34(0.849-2.127)$ & $1.918(1.116-3.296)^{*}$ \\
\hline No & $49(26.1)$ & $139(73.9)$ & 1 & 1 \\
\hline \multicolumn{5}{|c|}{ Previous anemia } \\
\hline Yes & $50(36.7)$ & $86(63.3)$ & $1.83(1.150-2.919)$ & $2.472(1.352-4.517)^{*}$ \\
\hline No & $53(24)$ & $167(76)$ & 1 & 1 \\
\hline \multicolumn{5}{|c|}{ Current anemia } \\
\hline Yes & $30(24.4)$ & $93(74.6)$ & $0.707(0.431-1.161)$ & $0.400(0.214-0.749)^{*}$ \\
\hline No & $73(31.3)$ & $160(68.7)$ & 1 & 1 \\
\hline \multicolumn{5}{|c|}{ Nutrition counseling } \\
\hline Yes & $96(30.8)$ & $215(69.2)$ & $2.424(1.045-5.622)$ & $1.533(0.598-3.927)$ \\
\hline No & $7(15.6)$ & $38(84.4)$ & 1 & 1 \\
\hline \multicolumn{5}{|c|}{ Knowledge of anemia } \\
\hline Yes & $36(39.5)$ & $55(60.5)$ & $1.93(1.169-3.20)$ & $1.062(0.531-2.122)$ \\
\hline No & $67(25.3)$ & $198(74.7)$ & 1 & 1 \\
\hline \multicolumn{5}{|c|}{ Knowledge of IFA } \\
\hline Yes & $54(40.9)$ & $78(59.1)$ & $2.47(1.546-3.955)$ & $1.846(0.919-3.708)$ \\
\hline No & $49(21.9)$ & $175(79.1)$ & 1 & 1 \\
\hline \multicolumn{5}{|c|}{ Participate in $\mathrm{CC}$} \\
\hline Yes & $69(34.7)$ & $130(64.3)$ & $1.920(1.189-3.100)$ & $1.296(0.730-2.301)$ \\
\hline No & $34(21.6)$ & $123(79.4)$ & 1 & 1 \\
\hline \multicolumn{5}{|c|}{ Family support } \\
\hline Yes & $93(32)$ & $197(68)$ & $2.644(1.291-5.413)$ & $2.043(0.946-4.412)$ \\
\hline No & $10(15.2)$ & $56(84.8)$ & 1 & 1 \\
\hline \multicolumn{5}{|l|}{ Trimester } \\
\hline Second & $29(24.3)$ & $90(75.7)$ & 1 & 1 \\
\hline Third & $74(31.2)$ & $163(68.8)$ & $1.409(0.854-2.324)$ & $1.773(0.968-3.248)$ \\
\hline
\end{tabular}

*statistically significant $(\mathrm{P}<0.05), \mathrm{CC}=$ Community conversion

\section{Discussion}

Pregnant women are one of the vulnerable populations to develop iron deficiency anemia. The World Health Organization recommends giving all pregnant women a standard dose of $60 \mathrm{mg}$ iron and $400 \mu \mathrm{g}$ folic acid daily for 6 months duration. However, maternal adherence to the regimen plays a major role in the prevention and treatment of iron deficiency anemia $[19,22]$. The aim of this study was to compare the rates of adherence and identify factors associated with IFA supplementation among urban and rural pregnant women attending antenatal clinics in North Western Zone of Tigray, Ethiopia, 2014.

This study found that the self-report adherence rate of the pregnant women in the urban and rural pregnant women was $37.2 \%$ (95\% CI, 32.26\%-42.25\%) and $28.9 \%$ (95\%CI, $24.4 \%$ $33.81 \%$ ) respectively. This result indicated that there was no significant difference among urban and rural pregnant women with regard to adherence to the supplementation. To the best of our knowledge, there was no previous study conducted for comparative purposes. However, this result was inconsistent with other cross-sectional studies conducted in India, in which urban residents pregnant women were $35 \%$ higher to be adherent as compared to rural residents pregnant women $(\mathrm{AOR}=1.35,95 \% \mathrm{CI}=1.04-1.74)[5]$ and Nigeria in which urban pregnant women were $56 \%$ higher to be adherent as compared to rural pregnant women $(\mathrm{AOR}=1.56,95 \% \mathrm{CI}=$ 1.14-1.84) [23]. And this might be due to similarity in their socio-economic status of the urban and rural pregnant women despite the subjects lived in different areas.

In the present study, adherence rate was better observed among pregnant women who had anemia during their first visit as compared to those pregnant women who had not anemia in the urban communities in which pregnant women 
who had anemia during the first visit were about $91.3 \%$ higher to be adherent to IFA supplementation as compared to pregnant women who had not anemia during the first visit $(\mathrm{AOR}=1.913,95 \% \mathrm{CI}=1.135-3.223)$. Similarly, adherence was better observed among pregnant women who had anemia during their first visit as compared to those pregnant women who had not anemia in the rural communities as well in which pregnant women who had anemia during the first visit were about 2.5 times higher to be adherent to IFA supplementation as compared to pregnant women who had not anemia during the first visit $(\mathrm{AOR}=2.472$, $95 \% \mathrm{CI}=1.352-4.517)$. The result of this study is consistent with other studies conducted in Malaysia $(\mathrm{p}=0.008,34.5 \%$ Vs 54.5), Kiambu, Kenya, $\left(\mathrm{X}^{2}=14.3, \mathrm{p}=0.001\right)$ and Tanzania $(\mathrm{p}<0.001, \mathrm{AOR}=10.81,74.9 \%$ Vs $21.2 \%(8.72-13.39)[7,24$, 25].

In the present study, adherence was better observed among pregnant women who were early registered for antenatal care service as compared to late registered women in the urban communities in which pregnant women who were early registered for antenatal care service were about $77.8 \%$ higher to be adherent to IFA supplementation as compared to pregnant women who were lately registered for antenatal service $(\mathrm{AOR}=1.778,95 \% \mathrm{CI}=1.076-2.936)$. Similarly, adherence was better observed among pregnant women who were early registered for antenatal care service as compared to late registered women in the rural communities in which pregnant women who were early registered for antenatal care service were about $91.8 \%$ higher to be adherent to IFA supplementation as compared to pregnant women who were lately registered for antenatal care service $(\mathrm{AOR}=1.918$, 95\% $\mathrm{CI}=1.116-3.296$ ).

Similar results were reported by other studies conducted in Lucknow, India (AOR $=1.745,95 \% \mathrm{CI}=1.122-2.714)$ and Nepal $(A O R=1.03,95 \% \mathrm{CI}=1.01-1.04)[18,26]$.

In the present study, adherence was better among pregnant women who had four or more visits in the urban communities alone in which pregnant women who had at least four antenatal visits were about 3.78 times higher to be adherent to IFA supplementation as compared to pregnant women who were lately registered for antenatal care service $(\mathrm{AOR}=3.784$, $95 \% \mathrm{CI}=2.073-6.909)$. This result is similar with other studies conducted in Egypt $(\mathrm{t}=2.069, \mathrm{p}$-value $=0.040)$, Tanzania $(\mathrm{AOR}=1.13,95 \% \mathrm{CI}=0.97-1.33)$ and Philippines $(\mathrm{p}=0.001$, $\mathrm{AOR}=0.683,95 \% \mathrm{CI}=0.315-0.532)[4,7,27]$.

In the present study, the incidence of anemia was significantly lower among pregnant women who adhered to IFA supplementation as compared to those women who did not adhere to IFA supplementation in the urban communities in which pregnant women who adhered to IFA supplementation were about $59.2 \%$ lower risk to be anemic as compared to pregnant women who did not adhere to IFA supplementation $\quad(\mathrm{AOR}=0.408, \quad 95 \% \mathrm{CI}=0.224-0.744)$. Similarly, the incidence of anemia was significantly lower among pregnant women who adhered to IFA supplementation as compared to those women who did not adhere to IFA supplementation in the rural communities in which pregnant women who adhered to IFA supplementation were about $60 \%$ lower risk to be anemic as compared to pregnant women who did not adhere to IFA supplementation ( $\mathrm{AOR}=0.400$, $95 \% \mathrm{CI}=0.214-0.749)$. This result was similar with other studies conducted in Egypt (37.5\% Vs 62.5\%), Nigeria (15\% $\left.\mathrm{Vs} 18 \%, \mathrm{X}^{2} 7.5, \mathrm{p}=0.006\right)$ and rural Malaysia $(34.5 .0 \% \mathrm{Vs}$ $50 \%)[4,23,24]$.

In the present study, adherence of the pregnant women to IFA supplementation was less observed among pregnant women ageing greater than 25 years as compared to pregnant women ageing less than 25 years in the rural communities in which pregnant women ageing greater than 25 years were about $47.3 \%$ less adhered to IFA supplementation as compared to pregnant women ageing less than than 25 years $(\mathrm{AOR}=0.527, \quad 95 \% \mathrm{CI}=0.315-0.881)$. This result is inconsistent with other studies conducted in Tanzania $(\mathrm{AOR}=1.2595 \% \mathrm{CI}=1.08-1.43)$, Lucknow, India $(\mathrm{AOR}=$ $1.836,95 \%$ CI $=1.020-3.305)$ and Nepal $(p=0.001$, $\mathrm{AOR}=1.03,95 \% \mathrm{CI}=1.02=1.04)[18,7,26]$.

This might be due to the fact that pregnant women in the rural communities ageing less than 25 years may have better educational exposure as compared to ageing greater than 25 years although educational status of the pregnant women was not statistically significant.

\section{Strength and Limitation of the Study}

Among the notable strengths of the study is that adequate sample size. Among the limitations of the study is that information on adherence rate was from self report of in taking tablets. Therefore, we could not reject the possibility of reporting pregnant women who did not actually ingest the tablets. Other methods like pill count method may predict adherence rate better in future studies.

\section{Conclusions and Recommendations}

This study highlighted a number of important findings. First, adherence rate with IFA supplementation among pregnant women attending antenatal care both in urban and rural areas was found to be low. Second, early registration for antenatal care, number of antenatal visits and previous anemia were statistically significant independent positive predictors for maternal adherence to IFA supplementation. Conversely, being currently anemic was statistically significant independent negative predictors for maternal adherence to IFA supplementation in the urban pregnant women. On the other hand, early registration for antenatal care and previous anemia were statistically significant independent positive predictors for maternal adherence to IFA supplementation. Conversely, being currently anemic and elder age were statistically significant independent negative predictors for maternal adherence to IFA supplementation in the rural pregnant women. The findings of this study highlighted a comprehensive nutrition education and health promotion programs should focus on the importance of adherence to IFA tablets to improve adherence 
to IFA both in urban and rural pregnant women. Health workers should be aware of factors affecting adherence to the pregnant women and try to improve their adherence to ironfolic acid tablets both for urban and rural pregnant women. Special attention should be given for pregnant women having anemia during antenatal visits.

\section{Acknowledgement}

The authors acknowledge Save the children/UK for its financial support to make easy our work in the research process. The authors would also like to thank health departments for giving permission to carry out the study at respective health institutions. We are indebted to all pregnant women involved in this study.

\section{References}

[1] Lucy N, Gathig.I: Factors Influencing Utilization of Iron and Folic Acid supplementation Services among Women Attending Antenatal Clinic at Nyeri Provincial Hospital Kenya. University of Nairobi/Dissertation.2011: http://www.kemri.org.com

[2] Yakoob YM, Bhutta AZ: Effect of routine iron supplementation with or without folic acid on anemia during pregnancy.BMC Public Health 2011, 11(Suppl 3):S21. http://www .biomedcentral .com/ 1471-2458/11/S3/S21

[3] Haidar AJ, Pobocik SR: Iron deficiency anemia is not a rare problem among women of reproductive ages in Ethiopia: BMC Blood Disorders. 2009, 9:7, doi:10.1186/1471-2326-9-7

[4] ZAKIA M, Ibrahim, M.D, Seham Abd El-Hamid, M.D, Hend Mikhail, M.Sc, Maged S, Khattab M.D: Assessment of Adherence to Iron and Folic Acid Supplementation and Prevalence of Anemia in Pregnant Women Ismailia governorate, Egypt. Med. J. Cairo Univ., Vol. 79, No. 2, June 2011, 115-121, www.medicaljournalofcairouniversity.com

[5] Begum S. Factors associated with adherence to Iron Folic acid supplementations during Pregnancy in Uttar Pradesh: Volume 14 (2), 2012, www.ijmch.org

[6] Sengpiel V, Bacelis , Myhre R, Solveig Myking2, Devold A, Haugen M, BrantsæterA, Meltzer H, Nilsen RM: Folic acid supplementation, dietary folate intake during pregnancy and risk for spontaneous preterm delivery: a prospective observational cohort study. BMC Pregnancy and Childbirth 2013 13:160. doi:10.1186/1471-2393-13-160

[7] Ogundipe O, Hoyo C, Stbye T, Oneko O, Manongi R, Terje R, Kjersti D: :factors associated with prenatal folic acid and iron supplementation among 21,889 pregnant women in urban areas Tanzania: a cross-sectional hospital based study. BMC Public Health 2012; 12:481. http://www.biomedcentral.com/1471-2458/12/481

[8] Marquardt H: hematological conditions. Family practice obstetrics, 2000; section E: 209.

[9] Lacerte $P$, Pradipasen $M$, Temcharoen $P$, Imamee $N$, Vorapongsathorn T: Determinants of Adherence to Iron/Folate Supplementation During Pregnancy in Two Provinces in Cambodia. Asia Pac J Public Health 2011;23(3):315-23.
[10] Bilimale A, Anjum J, Sangolli HN, Mallapur M: Improving Adherence to Oral Iron Supplementation during pregnancy. AMJ 2010; 3(5):281-90.

[11] Ethiopian Central Statistical Agency and ICF International: 2011 Ethiopia Demographic and Health Survey: Key Findings. Calverton, Maryland, USA: CSA and ICF International; 2012.: http://www.measuredhs.com.

[12] SPRING/FMOH: A Rapid, Initial Assessment of the Distribution and Consumption of Iron-Folic Acid Tab-lets through Antenatal Care in Ethiopia in selected four regions: March, 2013: www.spring-nutrition.org.

[13] Mahomed, K: Iron supplementation in pregnancy. Cochrane Database of systematic Reviews; 2000, Issue-1; http://www.thecochranelibrary.com

[14] FMOH. National guideline for control and prevention of micronutrient deficiencies. Addis Ababa: Family Health Department, Federal Ministry of Health, Government of Ethiopia, 2009.

[15] WHO: Iron and Folic acid Supplementation. Standards for Maternal \& Neonatal Care. Integrated Management of Pregnancy and Childbirth (IMPAC). Vol. 1.8, Geneva, Switzerland: World Health Organization. Department of Making Pregnancy Safer (MPS):2006, 1-6. http://www.thecochranelibrary.com

[16] WHO, Guideline: Daily iron and folic acid supplementation in pregnant women: 2006, issue-2: (http://www.who.int/about/licensing/copyright_form/en/index. html).

[17] FMOH: Programme implementation manual of national nutrition programme, June 2013-June 2015 Addis Ababa, Ethiopia.

[18] Kulkarni B, Christian P, C LeClerq S, K Khatry KS: Determinants of compliance to antenatal micronutrient supplementation and women's perceptions of supplement use in rural Nepal. Public Health Nutrition: May 2009,13(1), 8290: 19

[19] Galloway R, McGuire J: Determinants of compliance with iron supplementation: supplies, side effects, or psychology? Soc Sci Med. 2007; 39:381-390.

[20] STEINER J.F, EARNEST M.A: The language of medicationtaking. Ann. Intern. Med., 132: 926-930, 2000.

[21] Centers for Disease Control and Prevention. Pregnancy risk assessment monitoring system(PRAMS), phase 5 standard questions, 2007: http://www.pramS.org.com

[22] Zerfu AT, Ayele TH: Micronutrients and pregnancy; effect of supplementation on pregnancy and pregnancy outcomes: a systematic review. Nutrition Journal 2013 12:20. doi:10.1186/1475-2891-12-20

[23] Dairo MD, Lawovin TO: Demographic factors determining compliance to iron supplementation in pregnancy in Oyo State, Nigeria. Nigerian Journal of Medicine 2007; 15: 241-4.

[24] Thirukkanesh S, Zahara AM: compliance to vitamin and mineral supplementation among pregnant women in urban and rural areas of Malaysia.Pakistan journal of nut.9(8): 744750,2010 
[25] Lynette A: Factors associated with adherence to iron/folate supplementation among pregnant women attending antenatal clinic at thika district Hospital in kiambu county, Kenya. University of

Kenyata/diss.2013:

http://www.linetaoko@yahoo.com

[26] Roy MP, Mohan U, Singh SK, Singh VK, Srivastava AK: Socio-Economic Determinants of Adherence to Iron and Folic Acid Tablets among Rural Ante-natal Mothers in Lucknow, India. Natl J Community Med 2013; 4(3):386-391.
[27] Lutsey LP, Dawe D, Villate E, Valencia S, Lopez O: Iron supplementation compliance among pregnant women in Bicol, Philippines. Public Health Nutr 2008, 11:76-82. 